\title{
Tissue-specific knockout of E-cadherin (Cdh1) in developing mouse gonads causes germ cells loss
}

\author{
Rafal P Piprek¹, Michal Kolasa², Dagmara Podkowa', Malgorzata Kloc ${ }^{3,4,5}$ and Jacek Z Kubiak ${ }^{6,7}$ \\ ${ }^{1}$ Department of Comparative Anatomy, Institute of Zoology and Biomedical Research, Jagiellonian University, \\ Krakow, Poland, ${ }^{2}$ Institute of Systematics and Evolution of Animals, Polish Academy of Sciences, Krakow, Poland, \\ ${ }^{3}$ The Houston Methodist Research Institute, Houston, Texas, USA, ${ }^{4}$ Department of Surgery, The Houston Methodist \\ Hospital, Houston, Texas, USA, ${ }^{5}$ University of Texas, MD Anderson Cancer Center, Houston TX, USA, ${ }^{6}$ Univ Rennes, \\ CNRS, Institute of Genetics and Development of Rennes, UMR 6290, Cell Cycle Group, Faculty of Medicine, \\ Rennes, France and ${ }^{7}$ Laboratory of Regenerative Medicine and Cell Biology, Military Institute of Hygiene and \\ Epidemiology (WIHE), Warsaw, Poland
}

Correspondence should be addressed to R P Piprek; Email: rafal.piprek@uj.edu.pl

\begin{abstract}
The normal course of gonad development is critical for the sexual development and reproductive capacity of the individual. During development, an incipient bipotential gonad which consists of unorganized aggregate of cells, must differentiate into highly structured testis or ovary. Cell adhesion molecules (CAMs) are a group of proteins crucial for segregation and aggregation of different cell types to form different tissues. E-cadherin ( $C d h 1)$ is one of the CAMs expressed in the developing gonads. We used tissue-specific knockout of $\mathrm{Cdh} 1$ gene in $\mathrm{OCT}_{4}^{+}$germ cells and, separately, in $\mathrm{SF}^{+}$somatic cells of developing gonads. The knockout of E-cadherin in somatic cells caused decrease in the number of germ cells, while the knockout in the germ cells caused their almost complete loss. Thus, the presence of E-cadherin in both the germ and somatic cells is necessary for the survival of germ cells. Although the lack of E-cadherin did not impair cell proliferation, it enhanced apoptosis, which was a possible cause of germ cell loss. However, the somatic cells of the gonad differentiated normally into Sertoli cells in the testis cords, and into follicular cells in the ovaries. The testis and ovigerous cords maintained their integrity; they were covered by continuous basement membranes. The testicular interstitium with steroidogenic fetal Leydig cells did not show any noticeable changes. However, in the female gonads, because of the lack of germ cells, the ovarian follicles were absent. The sex determination and sexual differentiation of the gonad were not impaired. These results underscore an important role of E-cadherin in germ cell survival and gonad development.

Reproduction (2019) 158 147-157
\end{abstract}

\section{Introduction}

Cell adhesion is crucial for development of the embryo. Every cell of a given type produces a set of cell typespecific adhesion molecules (CAMs) on its surface. Because most of the CAMs interact homotypically, the cells of the same type are able to recognize and adhere to each other and form a specific tissue. Because CAM gene family contains at least 220 genes (Piprek et al. 2017), this process has a very high degree of specificity and complexity.

Gonads, both testes and ovaries, are composed of several cell types. In the developing testes, the germ cells are enclosed by differentiating Sertoli cells within elongated structures termed the testis cords (Chen \& Liu 2016, Piprek et al. 2016). The cords are enclosed by the basement membrane abutted by the peritubular myoid cells. The space between testis cords is occupied by the interstitial cells, including steroidogenic Leydig cells (Piprek et al. 2010). The developing ovaries contain small groups of germ cells, called the ovarian cysts, which are enclosed by differentiating follicular cells. The space between the cysts is filled with the stromal cells. It is unknown how, during gonad development, these different cell types form, segregate and adhere to each other to establish different tissues. We identified expression patterns of 83 genes related to cell adhesion in the germ cells and somatic cells of developing mouse testes, and 68 genes in developing mouse ovaries (Piprek et al. 2017). We showed previously that there is a sex-specific difference in CAMs expression between male and female germ cells, and especially between male and female supporting cells (Sertoli and follicular cells respectively in testes and ovaries). These results prompted us to study in details the role of selected CAMs in gonad development.

E-cadherin (epithelial cadherin), encoded by $C d h 1$ gene, is highly expressed in the germ cells of developing gonads (Mackay et al. 1999, Piprek et al. 2017). There is also low level of expression of E-cadherin in somatic 
cells of developing mouse gonads of both sexes (Piprek et al. 2017). The developing mouse gonads cultured in vitro in the presence of anti-E-cadherin antibodies, which block E-cadherin-mediated cell adhesion, showed lower number and mislocalization of the germ cells (Bendel-Stenzel et al. 2000, Di Carlo \& De Felici 2000).

Despite these significant findings pointing to the importance of E-cadherin in gonads development, the exact role of E-cadherin in gonad development, and its role in the germ cells vs somatic cells remain unknown. The main obstacle in answering these questions is that the conventional (whole-body) knockout of E-cadherin in mouse is lethal, and the embryos fail to develop past 32-cell stage (Larue et al. 1994, Ohsugi et al. 1997). To overcome the embryonic lethality, we studied the role of E-cadherin in developing mouse gonads using conditional knockout with cre-loxP system. We used three mouse strains to deplete E-cadherin in the germ cells or somatic cells of developing gonads. A mouse strain with Cre recombinase under the control of Oct4 promoter (Greder et al. 2012) was used to delete E-cadherin specifically in the germ cells. A mouse strain expressing cre recombinase under the control of $\mathrm{Sf1}$ (Nr5a1) promoter (Dhillon et al. 2006) was used to induce cre expression in somatic cells of developing gonads. The octamer-binding transcription factor 4 (OCT4) is a marker of germ cells and the steroidogenic factor 1 (SF1) is a marker of coelomic epithelium, which gives rise to majority of somatic cell types in developing gonads (Ikeda et al. 1994). The SF1+ cells of coelomic epithelium give rise to the Sertoli cells and some interstitial cells in the testes, and the follicular cells and some theca cells in the ovaries (Albrecht \& Eicher 2001, DeFalco et al. 2011, Liu et al. 2015). Both strains (OCT4-cre and SF1cre) were crossed with a mouse strain, which had loxP sequences flanking a segment (from exon 6 to 10) of the Cdh1 gene (Boussadia et al. 2002). We studied the effect of E-cadherin knockout using light microscope analysis, immunostaining and RT-qPCR.

\section{Materials and methods}

\section{Animals}

The study was approved by the I Local Commission for Ethics in Experiments on Animals. The animals were bred in the Animal Facility at the Jagiellonian University (Krakow, Poland). Three transgenic mouse lines used in this study were from Jackson Laboratory.

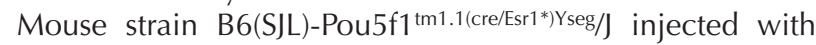
tamoxifen was used for the induction of Cre recombinase expression in the germ cells expressing Oct4 (Greder et al. 2012). Pregnant mice were injected with tamoxifen three times ( $2 \mathrm{mg} / 40 \mathrm{~g}$ body mass dissolved in sunflower oil) at embryonic days E10.5, E11.5 and E12.5. The sunflower oil injection was used as a control. Cdh 1 gene coding for E-cadherin was deleted in B6.129-Cdh $1^{\mathrm{tm}} \mathrm{K} \mathrm{Kem} / \mathrm{J}$ mouse strain, which has loxP sites flanking exons 6-10 (Boussadia et al. 2002). Mouse strain
$\operatorname{Tg}(\mathrm{Nr} 5 \mathrm{a} 1$-cre) 7 Lowl/J (Dhillon et al. 2006) was used for Cre recombinase expression in the somatic cells (which express Sf1) of the gonads. The number of studied individuals is shown in Supplementary Table 1 (see section on supplementary data given at the end of this article).

Timed matings were performed by placing a male with two females overnight. The following morning, females were checked for the presence of the vaginal plug, and the pregnancies were estimated as E0.5 (embryonic day). Females were killed by spinal dislocation at embryonic days: E10.5, E11.5, E12.5, E13.5, E14.5, E16.5 and E18.5, and the newborns were killed at 1 and $2 \mathrm{dpp}$ (days post partum).

\section{Genotyping}

The sex of all studied individuals was established by the genotyping using primers to detect Sly (Y chromosome) and XIr (X chromosome) (McFarlane et al. 2013). Primers used to genotype $\mathrm{Cre}^{+}$and floxed specimens are listed in Supplementary Table 2. A standard PCR protocol was used for genotyping.

\section{Gonad, RNA isolation and real-time quantitative PCR}

Total RNA was isolated from fetal or newborns gonads using TRIzol, and further purified with RNeasy Mini kit according to the manufacturer's protocol (Qiagen). Total RNA in RNase-free water was stored at $-80^{\circ} \mathrm{C}$ and used for multigene $\mathrm{qPCR}$ analysis. 50 ng RNA was reverse-transcribed into cDNA using random primers and SuperScript III Reverse Transcriptase (Invitrogen, 18080044) according to the manufacturer's protocol. A list of primers is shown in Supplementary Table 2. RT-qPCR was performed in $5 \mu \mathrm{L}$ reactions using SYBR Green Master Mix (Life Technologies, 4312704) on a 7500 Fast Real-Time PCR System (Applied Biosystems) with universal cycling parameters and analyzed as previously described (Svingen et al. 2009). $A c t b$ was used as a reference gene. Statistical analysis was performed using initially the nonparametric ANOVA KruskalWallis test followed by the Tukey's test. Statistica 7.0 software was used for the analyses.

\section{Gonadal cell isolation and sorting}

In order to check the effectiveness of the knockout, we analyzed the expression of $c r e$ and $C d h 1$ genes separately in isolated SSEA-positive germ cells and Pcdh18-positive somatic cells. We previously showed that protocadherin 18 (Pcdh18) is highly expressed in the supporting and interstitial/stromal cells, but not in the germ cells of developing mouse gonads of both sexes (Piprek et al. 2017). SSEA1 is a marker of germ cells previously used for their isolation (Durcova-Hills et al. 1999). The gonads were dissected at E10.5, E11.5, E13.5, E16.5, 2 $d p p$ and were incubated in $250 \mu \mathrm{L} 0.25 \%$ Trypsin-EDTA (Sigma, \#T4049) at $37^{\circ} \mathrm{C}$ for $5-10 \mathrm{~min}$ as previously described (Piprek et al. 2017). After tissue dissociation, the enzyme solution was replaced with $400 \mu \mathrm{L}$ PBS. Cells were centrifuged for $10 \mathrm{~min}$ at $9,500 \mathrm{~g}$, and the cell pellet was resuspended in $3 \%$ BSA/PBS containing antibodies $(10 \mu \mathrm{g} / \mathrm{mL}$ DyLight650conjugated anti-SSEA1, Invitrogen \#MA1-022-D650, and 
$10 \mu \mathrm{g} / \mathrm{ml}$ FITC-conjugated anti-Pcdh18, Biorbyt, \#orb3038) and incubated for $30 \mathrm{~min}$ at RT. Subsequently, cells were centrifuged for $10 \mathrm{~min}$ at 9,500 $\mathrm{g}$ and resuspended in PBS. For cell sorting the MoFlo XDP cytofluorimeter with a sorter (Beckman Coulter) was used. Cells were sorted depending on DyLight 650 and FITC signal. The cells were collected into lysis buffer (DNA/RNA Shield, Zymo Research \#R1100). Pooled gonads from three fetuses were used for each time point and experiments were repeated three times. Total RNA was isolated using TRIzol, purified with RNeasy Mini kit according to the manufacturer's instructions (Qiagen), and RT-qPCR was performed as described above. A list of primers is shown in Supplementary Table 2. The purity of isolated cells was confirmed by analysis of expression of germ cell markers (Oct4 and Mvh) and somatic cell markers (Sox9, Fox/2) (Supplementary Figs 1E, F and 2E, F).

\section{Histology and immunohistochemistry}

Dissected gonads were fixed in Bouin's solution, dehydrated and embedded in paraffin (Paraplast, Sigma, P3683). Histological staining was performed according to Debreuill's trichrome method as previously described (Kiernan 1990, Piprek et al. 2012). For immunochemistry, heat-induced epitope retrieval was conducted in sodium citrate buffer ( $10 \mathrm{mM}$ sodium citrate, $0.05 \%$ Tween-20, $\mathrm{pH}$ 6) at $95^{\circ} \mathrm{C}$ for $20 \mathrm{~min}$. Subsequently, the sections were blocked with $3 \%$ $\mathrm{H}_{2} \mathrm{O}_{2}$ and $10 \%$ goat serum (Sigma, G9023), and incubated with primary antibodies (rabbit polyclonal anti-AMH, Santa Cruz Biotechnology, sc-166752; anti-collagen I, Abcam, ab34710; anti-Cyp17a1, Abcam, ab125022; anti-PCNA, Abcam, ab18197; anti-cleaved caspase 3, Assay BioTech, L0104; anticre recombinase, Abcam, ab190177; anti-E-cadherin, Abcam, ab152102; anti-TRA98, Abcam, ab82527) at $4^{\circ} \mathrm{C}$, overnight, followed by the UltraVision Quanto Detection System (ThermoFisher, TL-125-QHD). Mayer's hematoxylin was used as a counterstain. Sections were examined under Nikon Eclipse E600 microscope. The germ cells were recognized due to their bigger size and the presence of larger and hematoxylin pale-stained nuclei as compared to the somatic cells.

\section{Cell counting}

The sections of all gonads from the animals killed at E18.5 were immunostained (PCNA, caspase 3, Cyp17a1 and TRA98), and the number of PCNA-, caspase 3-, Cyp17a1- and TRA98positive cells was calculated in the $10000 \mu \mathrm{m}^{2}$ area in five cross-sections from each gonad using Image software. Average values and standard deviation were calculated using Microsoft Excel software. The number of cells in the knockout gonads was compared to the control using $\chi^{2}$ test. Statistical data were analyzed using Statistica 6 PL Software (Krakow, Poland).

\section{Results}

\section{The effectiveness of genetic knockout}

First we checked the effectiveness of the knockout using RT-qPCR to assess the level of expression of cre recombinase and Cdh 1 separately in germ and somatic cells isolated from $X Y$ and $X X$ mouse gonads. A high expression of cre gene under the control of Oct4 promoter was detected in embryonic $X Y$ and $X X$ gonads from E11.5 (Supplementary Fig. 1A and B). The expression of cre mRNA decreased after E16.5 (Supplementary Fig. 1A and B). The expression of Cdh 1 was vestigial at E13.5 and absent from E16.5 (Supplementary Fig. 1C and D), which proved the effectiveness of the knockout in the germ cells.

The expression of cre recombinase under the control of Sf1 promoter was observed from E11.5 onward (Supplementary Fig. 2A and B). The expression of Cdh1 was visibly lower at E11.5, and absent from E13.5 in XY gonads and from E16.5 in XX gonads (Supplementary Fig. 1C and D), which proved the effectiveness of the knockout in the somatic cells.

\section{Knockout of E-cadherin (Cdh1) in OCT4-positive germ cells of developing mouse gonads}

Knockout of Cdh1 (E-cadherin) in germ cells (Oct4$\mathrm{cre}^{+}\left(d h 1^{f l / f l}\right)$ caused a dramatic decrease in germ cell number (Fig. 1 and Supplementary Tables 3, 4). The majority of studied gonads of both sexes $(86 \%)$ were completely deprived of germ cells. The loss of germ cells (first noticeable at stage E16.5) correlated with a decrease in the expression of germ cell marker Mvh (Fig. 2A and B) and a decrease in the size of the gonads. The testes of knockout males at E18.5 were smaller (the diameter of cross section at the widest area was $587 \pm 102.95 \mu \mathrm{m})$ than the control testes $(668 \pm 72.65 \mu \mathrm{m})$. The ovaries of knockout females at E18.5 were also smaller $(323 \pm 98.45 \mu \mathrm{m})$ than the control ovaries $(456 \pm 64.08 \mu \mathrm{m})$. The effects of

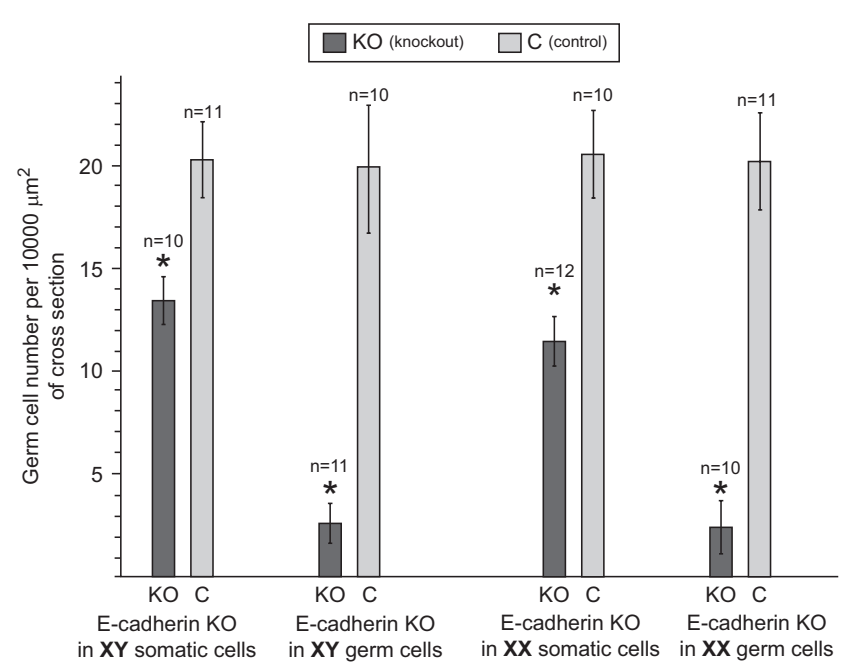

Figure 1 Germ cell number in the control and E-cadherin knockout gonads at E18.5. The number of germ cells is significantly lower in knockout $X Y$ and $X X$ gonads than in the control. $* P<0.05$ (by $\chi^{2}$ ). 

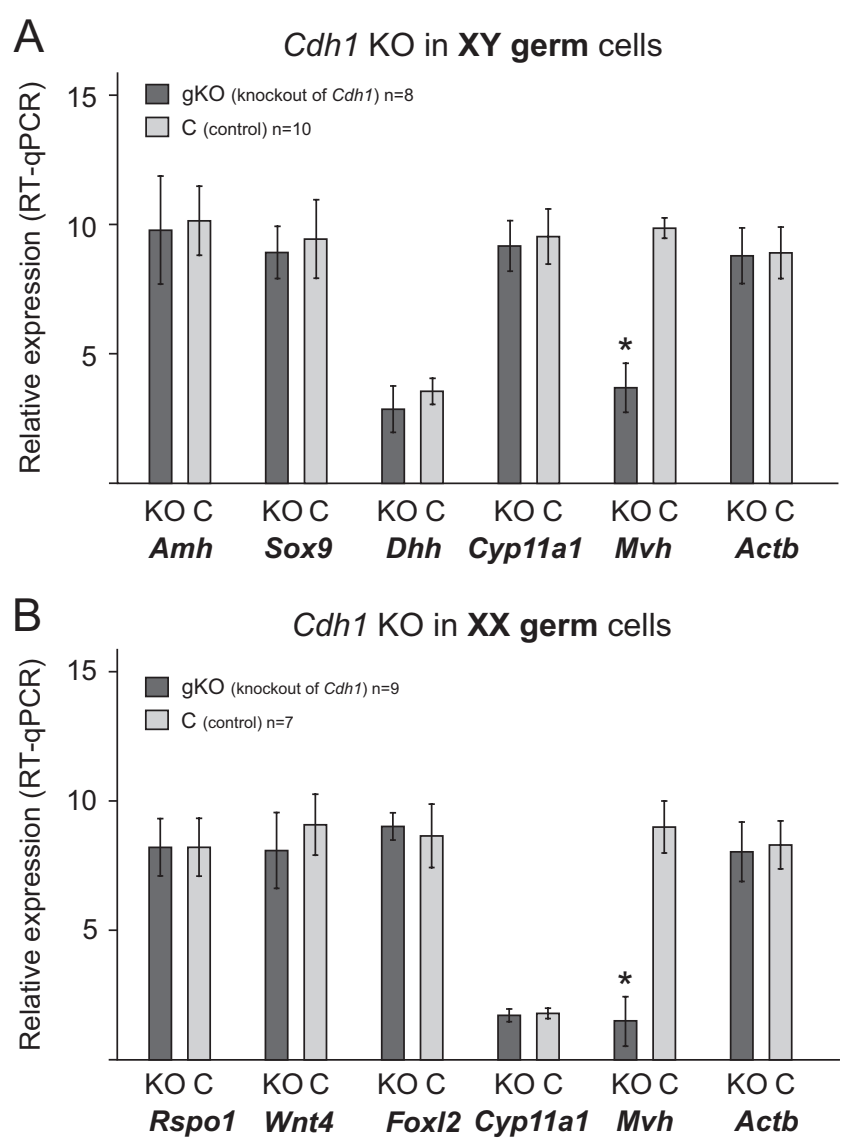

Figure 2 Gene expression in control and E-cadherin knockout in the germ cells at E18.5. The expression of Mvh is significantly lower in knockout $\mathrm{XY}(\mathrm{A})$ and $\mathrm{XX}(\mathrm{B})$ gonads than in the control. ${ }^{*} P<0.05$ (by $\left.\chi^{2}\right)$.

E-cadherin knockout in the testes and in the ovaries are summarized in Tables 1 and 2, respectively.

To check if the loss of germ cells resulted from the changes in the proliferation or apoptotic cell death, we studied the expression of PCNA (proliferating cell nuclear antigen) and caspase 3, respectively. The PCNA immunostaining and the number of proliferating cells did not reveal any significant differences between control and knockout female and male gonads (Fig. 3A, B, E, F and Supplementary Tables 5, 6). However, the number of caspase 3-positive (apoptotic) cells was much higher both in the knockout testes and the knockout ovaries, than in the control (Fig. 3C, D, G, H and Supplementary Tables 7,8$)$. This suggested that the lower number of germ cells observed in the knockout gonads possibly resulted not from the decreased proliferation but from the increased apoptotic cell death.

Histological analysis showed that the control testes were composed of numerous convoluted and tubular testis cords, in which the germ cells were enclosed by a monolayer of differentiating Sertoli cells (preSertoli cells); the basement membranes surrounded the testis cords, and the interstitium was located between the cords (Fig. 4A, C, G). The control ovary was filled with the irregularly shaped ovigerous cords in which germ cells were enclosed by differentiating follicular cells (pre-follicular cells); the basement membranes enclosed the ovigerous cords, and the stromal cells were located between the cords (Fig. 5A, C and E). The ovarian follicles (each follicle containing a single diplotene oocyte surrounded by follicular cells), which had separated from the ovigerous cords, were located near the medullary region of the ovary as early as at E18.5 (Fig. 5C).

The histological analysis of developing male gonads showed the presence of testis cords in both the knockout and control testes (Fig. 4A, B, C and D). Importantly, in the knockout testis cords no germ cells were visible (sterile cords) or only singular germ cells were present (Fig. 4F), while in control testis the testis cords were filled with numerous germ cells (Fig. 4E). To assess the changes in the testis cords, we performed immunostaining with Sertoli cells marker AMH (anti-müllerian hormone) and the basement membrane marker collagen I. AMH immunostaining showed the presence of Sertoli cells filling the center of the testis cords in both knockout and control testes (Fig. 4G and H). However, in the knockout testes, because of the lack of germ cells, the Sertoli cells did not form protrusions, which, normally, enclose the germ cells. The collagen I immunostaining showed that the knockout of E-cadherin in the germ cells did not

Table 1 Testes - effects of E-cadherin $\mathrm{KO}$ in $\mathrm{Oct} 4^{+}$germ cells and $\mathrm{Sf}^{+}$somatic cells.

\begin{tabular}{|c|c|c|c|}
\hline & Control & $\begin{array}{l}\text { Mutant phenotype E-cadherin KO in } \\
\text { germ cells }\end{array}$ & $\begin{array}{l}\text { Mutant phenotype E-cadherin } \mathrm{KO} \text { in } \\
\text { somatic cells }\end{array}$ \\
\hline Testis size & Normal & Smaller* & Smaller* \\
\hline Testis cords & Normal & Smaller* & Smaller* \\
\hline Germ cells & Normal number of germ cells & $\begin{array}{l}\text { Lower number of germ cells or sterile } \\
\text { gonad* }\end{array}$ & Lower number of germ cells* \\
\hline Sertoli cells & Continuous monolayer of Sertoli cells & Continuous monolayer of Sertoli cells & Continuous monolayer of Sertoli cells \\
\hline Basement membrane & Continuous & Continuous & Continuous \\
\hline Interstitium & Normal & Normal & Normal \\
\hline Fetal Leydig cells & Normal number & Normal number & Normal number \\
\hline Proliferation & Normal (high level) & Normal (high level) & Normal (high level) \\
\hline Apoptosis & Normal (low level) & Increased in the germ cells* & Increased in the germ cells* \\
\hline
\end{tabular}

*Indicates affected cells and structures. 
Table 2 Ovaries - effects of E-cadherin $\mathrm{KO}$ in Oct4 ${ }^{+}$germ cells and $\mathrm{Sf} 1^{+}$somatic cells.

\begin{tabular}{llll}
\hline & Control & Mutant phenotype E-cadherin KO in germ cells & $\begin{array}{l}\text { Mutant phenotype E-cadherin KO in } \\
\text { somatic cells }\end{array}$ \\
\hline Ovary size & Normal & Smaller* & Smaller* \\
Ovigerous cords & Normal & Smaller* & Smaller* \\
Germ cells & Normal number of germ cells & Lower number of germ cells or sterile gonad* & Lower number of germ cells* \\
Follicular cells & Present & Present & Present \\
Ovarian follicles & Present & Absent* & Absent* \\
Basement membrane & Continuous & Continuous & Continuous \\
Proliferation & Normal (high level) & Normal (high level) & Normal (high level) \\
Apoptosis & Normal (low level) & Increased* & Increased* \\
\hline
\end{tabular}

*Indicates affected cells and structures.

affect the integrity of the testis cords, which remained enclosed by continuous basement membrane (Fig. 4I and J). To check if the organization of the interstitium located between the testis cords was affected we studied immunolocalization of Cyp17a1 - a marker of fetal Leydig cells located in the interstitium. We did not find significant differences in number of steroidogenic cells between the knockout and control testes interstitium (Fig. 4K, L and Supplementary Table 9).

In the developing ovaries, the histological analysis showed the presence of ovigerous cords, whose borders were clearly visible in collagen I immunostaining (Fig. 5A, B, C, D, E and F). The most striking difference between the knockout and the control ovaries was a lower number or complete lack of the germ cells, and smaller ovigerous cords in the knockout (Fig. 5G and H). In the control ovaries, singular oocytes enclosed by a monolayer of follicular cells were present near the ovarian medulla as early as at E18.5, which indicated the formation of the ovarian follicles. In contrast, in the knockout ovaries, which lacked the germ cells, the ovarian follicles were absent (Fig. 5C and D). However, the knockout ovaries had the ovigerous cords. In order to exclude the effect of tamoxifen (used to induce cre expression) on gonadal development, we performed histological analysis of gonads from tamoxifen-treated animals. We did not observe any structural/histologic changes in the gonads from the tamoxifen-treated animals (data not shown).

In order to find out if/how the knockout of E-cadherin influenced gene expression in developing testes and ovaries, we studied the expression of male sex determination genes, that also are the markers of Sertoli cells (Amh, Sox9 and Dhh), and the expression of female sex determining genes, which are the markers of ovarian follicular cells (Rspo1, Wnt4, Fox/2). These genes are involved in male and female sex determination and testis and ovary differentiation. This analysis showed that the E-cadherin knockout did not affect the expression of these genes (Fig. 2A and B) and did not affect sex determination or sex ratio (the changes in the sex ratio could indicate sex reversal) (Supplementary Table 1). This shows that the lack of E-cadherin in the gonadal germ cells did not disrupt sex determination and did not cause sex reversal.

\section{Knockout of E-cadherin (Cdh1) in SF1-positive somatic cells of mouse gonads}

Knockout of Cdh1 (E-cadherin) in somatic cells (Sf1$\mathrm{Cre}^{+}\left(\mathrm{Cdh} 1^{\mathrm{fl} / \mathrm{fl})}\right.$ caused a decrease in germ cell number in both $X Y$ and $X X$ gonads starting from E16.5 onward. However, the this decrease in the germ cell number was much less severe than in the E-cadherin knockout in the germ cells (Fig. 1 and Supplementary Tables 3, 4). This germ cell loss was correlated with a decrease in the expression of the germ cell marker Mvh (Fig. 6A and B) and a decrease in the size of the gonads. The testes of knockout males at E18.5 were smaller (the diameter of cross section at the widest area was $618 \pm 97.98 \mu \mathrm{m})$ in comparison to the control $(653 \pm 78.23 \mu \mathrm{m})$. The ovaries of knockout females at E18.5 were also smaller $(390 \pm 76.34 \mu \mathrm{m}$ versus $452 \pm 54.05 \mu \mathrm{m})$. The effects of E-cadherin knockout in the testes and ovaries are summarized in Tables 1 and 2, respectively.

PCNA immunostaining showed the unchanged cell proliferation in the knockout gonads (Fig. 7A, B, E, F and Supplementary Tables 5, 6). However, the immunostaining of caspase 3 showed more apoptotic cells inside the testis and ovigerous cords in the developing knockout testes and ovaries in comparison to the controls (Fig. 7C, D, G, H and Supplementary Tables 7, 8). This indicates that the lower number of germ cells resulted not from a decline in the proliferation but from the enhanced apoptosis.

Histological analysis of control and knockout testes showed the presence of typical testis cords with the Sertoli cells forming a continuous monolayer epithelium (Fig. 8A, B, C and D). The number of germ cells was visibly lower than in the control (Fig. 8E and F). Immunostaining for AMH (marker of Sertoli cells) did not show any changes in the Sertoli cells (Fig. 8G and $\mathrm{H})$. Immunostaining for collagen I showed a continuous basement membrane enclosing the testis cords in the control and the knockout testes (Fig. 8I and J). This indicates that the integrity of Sertoli cell epithelium was not affected by the lack of E-cadherin. There was also 


\section{Control}

$X Y$
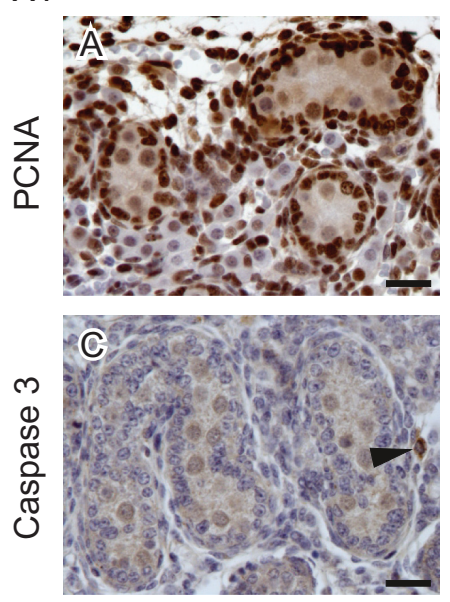

$\mathrm{XX}$
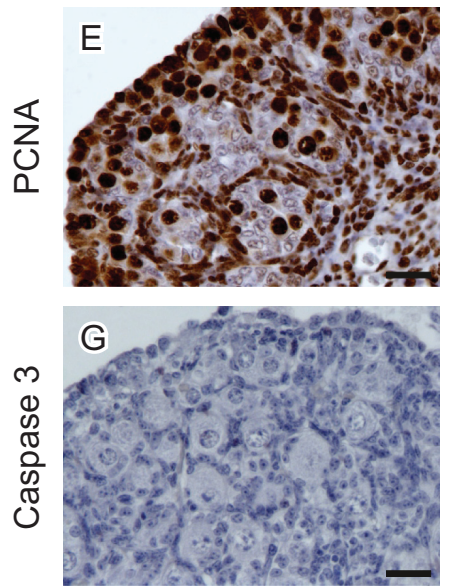

$\mathrm{KO}$ Oct4-cre ${ }^{+} \mathrm{Cdh} 1^{\mathrm{t} / \mathrm{t}}$
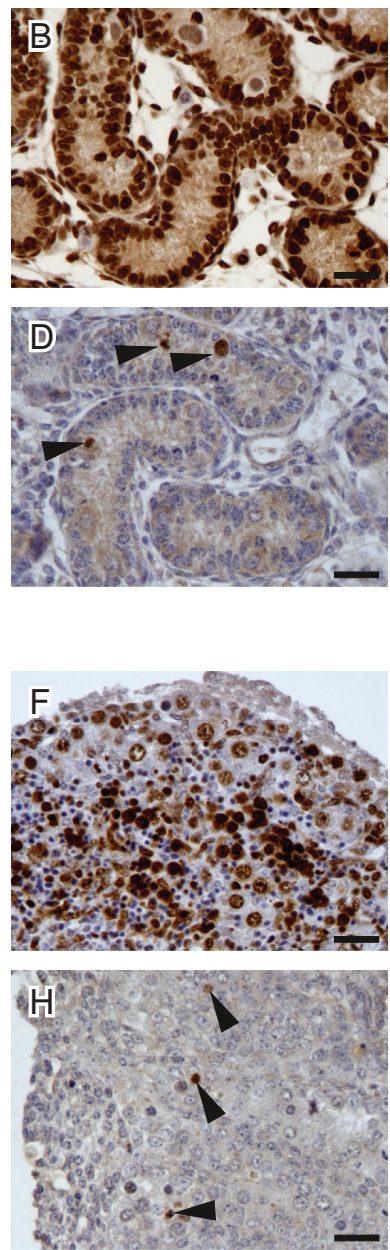

Figure 3 Proliferation (PCNA immunostaining) and apoptosis (caspase 3 immunostaining) in testes and ovaries in E-cadherin knockout in the germ cells at E18.5. Similar effect of PCNA immunostaining is visible in control (A) and knockout testis (B) indicating similar level of proliferation (Supplementary Table 5). The number of caspase

3 -positive (arrowheads) is higher in the knockout testis (D) than in the control testis (C) (Supplementary Table 7). The knockout (F) and control ovaries (E) show similar level of PCNA-positive cells number, however, the number of caspase 3-posotive cells is visibly higher in the knockout $(\mathrm{H})$ than in the control $(\mathrm{G})$ ovaries (Supplementary

Tables 6 and 8). Scale bar: $25 \mu \mathrm{m}$.

no significant change in the intersititum (which contains Cyp17a1-positive fetal Leydig cells) present between testis cords (Fig. 8K, L and Supplementary Table 9). However, the knockout testes had lower number of germ cells.

The developing knockout ovaries had lower number of germ cells, smaller ovigerous cords and lacked the ovarian follicles (Figs 1 and 9A, B, C, D, E, F, G, H).

The analysis of the expression of selected genes in the somatic cells specific knockout showed that the expression of testis specific genes (Sox9, Amh, Dhh) and ovarian genes (Rspo1, Wnt4, Foxl2) agreed with the

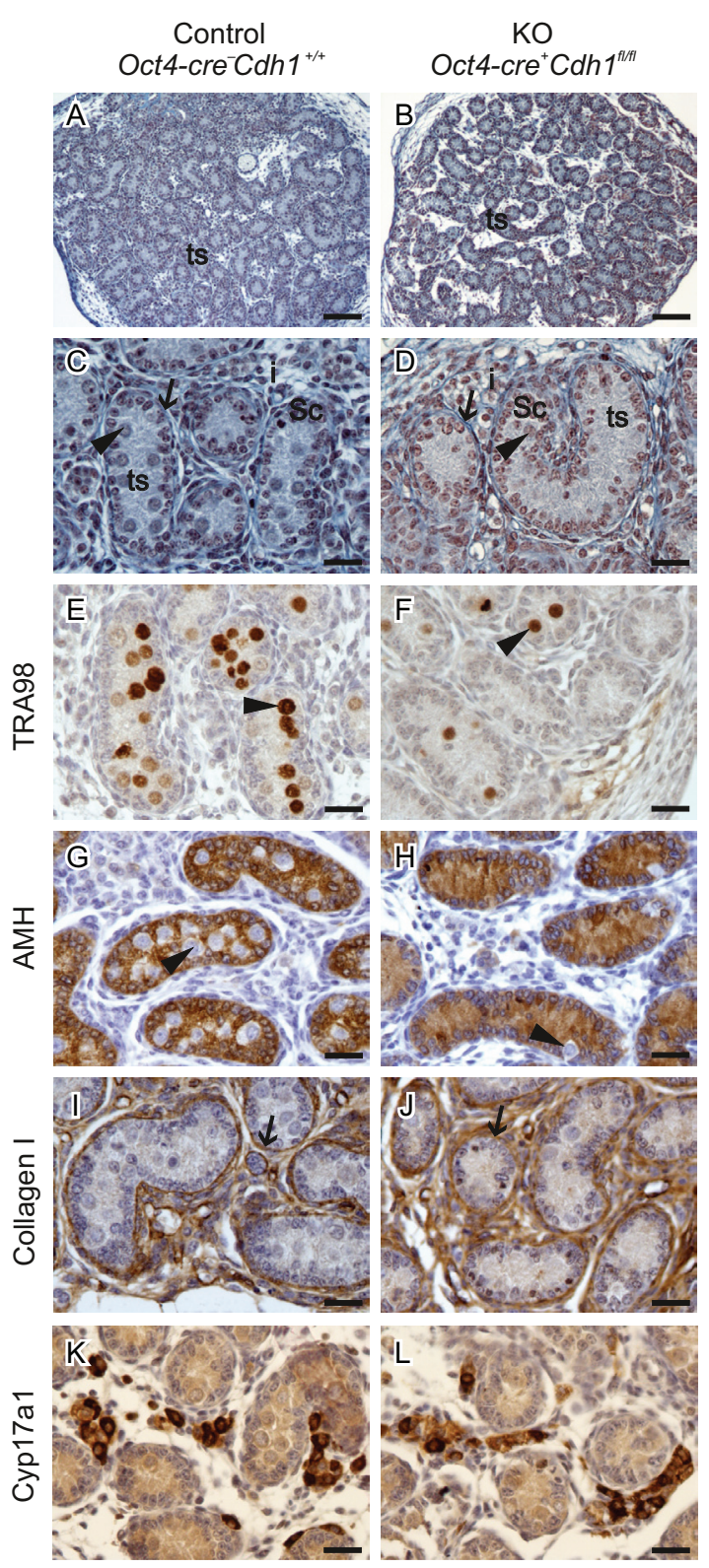

Figure 4 Histology of the testis in the control and E-cadherin knockout in the germ cells. (A and C) Testes of control individual (Oct4-Cre- $\mathrm{Cdh}^{+++}$) at stage E18.5; germ cells (arrowheads) are enclosed by the Sertoli cells (Sc); the whole testis cord (ts) is encapsulated by the basement membrane (arrow); interstitium (i) is located between the cords; trichrome staining. ( $\mathrm{B}$ and $\mathrm{D})$ The same testis structure is visible in the knockout testis (Oct4-Cre $\left.\mathrm{Cdh}^{+} \mathrm{f}^{\mathrm{flff} f}\right)$, however, in the knockout testis only few germ cells are present (arrowheads); trichrome staining. ( $E$ and $F$ ) The immunostaining of TRA98 shows that the number of germ cells (arrowheads) is significantly lower in the knockout than in control testis. The immunostaining of $\mathrm{AMH}$ in the control $(\mathrm{G})$ and knockout testis $(\mathrm{H})$ is similar, however, in the knockout testis cords, only singular germ cells (arrowheads) are present. Immunostaining of collagen I shows continuous basement membranes (arrows) enclosing each testis cord in control (I) and knockout (J) testes. Numerous Cyp17a1-positive cells are visible in control (K) and knockout (L) testes. Cyp17a1positive cells are fetal Leydig cells present in the interstitium. Scale bar: A and B: $100 \mu \mathrm{m} ; \mathrm{C}, \mathrm{D}, \mathrm{E}, \mathrm{F}, \mathrm{G}, \mathrm{H}, \mathrm{I}$ and J: $25 \mu \mathrm{m}$. 
genetic sex (XY and XX) (Fig. 6A and B). Also the sex ratio was not affected in the knockout gonads (Supplementary Table 1). Altogether, these results showed that the lack of E-cadherin in the gonadal somatic cells did not alter sex determination and did not cause sex reversal.

\section{Discussion}

We used targeted knockout technique, with Cre recombinase expression under the control of and Sf1 and Oct4 promoters, which allowed us to silent E-cadherin expression in the selected types of cells (germ cells or gonadal somatic cells) during the early stage of gonad development. Our experiment showed that (1) E-cadherin plays a role in gonad development, (2) E-cadherin expression in both germ and somatic cells is necessary for the survival of germ cells (and thus for the fertility of an individual), (3) E-cadherin is crucial for the formation of the ovarian follicles, (4) E-cadherin is not necessary for Sertoli cells and follicular cells differentiation or the formation of testis cords or ovigerous cords (and thus is not necessary for the sexual differentiation), (5) E-cadherin is not necessary for the formation of interstitium and steroidogenic cells and (6) E-cadherin is not necessary for sex determination of the gonad.

We can not exclude the possibility that in our experiment the E-cadherin was also deleted in other tissues expressing Sf1 such as the pituitary gland and hypothalamus. Nevertheless, previous studies showed that deletion of gene encoding FSH (folliclestimulating hormone, produced by pituitary gland and influencing gonads) did not influence gonad structure or number of germ cells, but rather caused development of gonad tumors and blocked primary ovarian follicle development from primordial follicles during maturation (Kumar et al. 1999). Similarly a lack of another pituitary hormone - LH (luteinizing hormone) did not influenced gonad development during fetal life, however, was crucial for stimulation of spermatogenesis during maturation (Themmen \& Huhtaniemi 2000). This indicated that phenotypes observed in our study are effects of E-cadherin ablation in the gonads, however, not in the hypothalamus or pituitary gland.

The E-cadherin is a calcium-dependent cell-cell adhesion molecule believed to be crucial for the formation and maintenance of the epithelium (van Roy \& Berx 2008). E-cadherin is expressed very early during mammalian development. Already in the twocell stage embryo, it is responsible for the adhesion of the blastomers. It is also crucial for the embryo compaction, which takes place in the late eight-cell stage mouse embryo (Larue et al. 1994, Ohsugi et al. 1997). It has been shown that E-cadherin is present on the surface of primordial germ cells (PGCs) from the moment they leave the hindgut and migrate toward the gonadal primordium and on the surface of germ cells in developing gonads (Mackay et al. 1999, Bendel-Stenzel et al. 2000, Piprek et al. 2017). In adults, E-cadherin is critical for the integrity of the epithelium in various organs (van Roy \& Berx 2008).

Mutations in E-cadherin are linked to the development and metastasis of breast and gastric carcinomas (Beavon 2000, Polyak \& Weinberg 2009). Depletion of E-cadherin usually leads to a decrease in cell adhesion strength, triggering cell motility, which is crucial for the metastasis. So far, there were no studies on the role of E-cadherin in gonad development in the mouse. There were two in vitro studies in which mouse gonadal primordia were

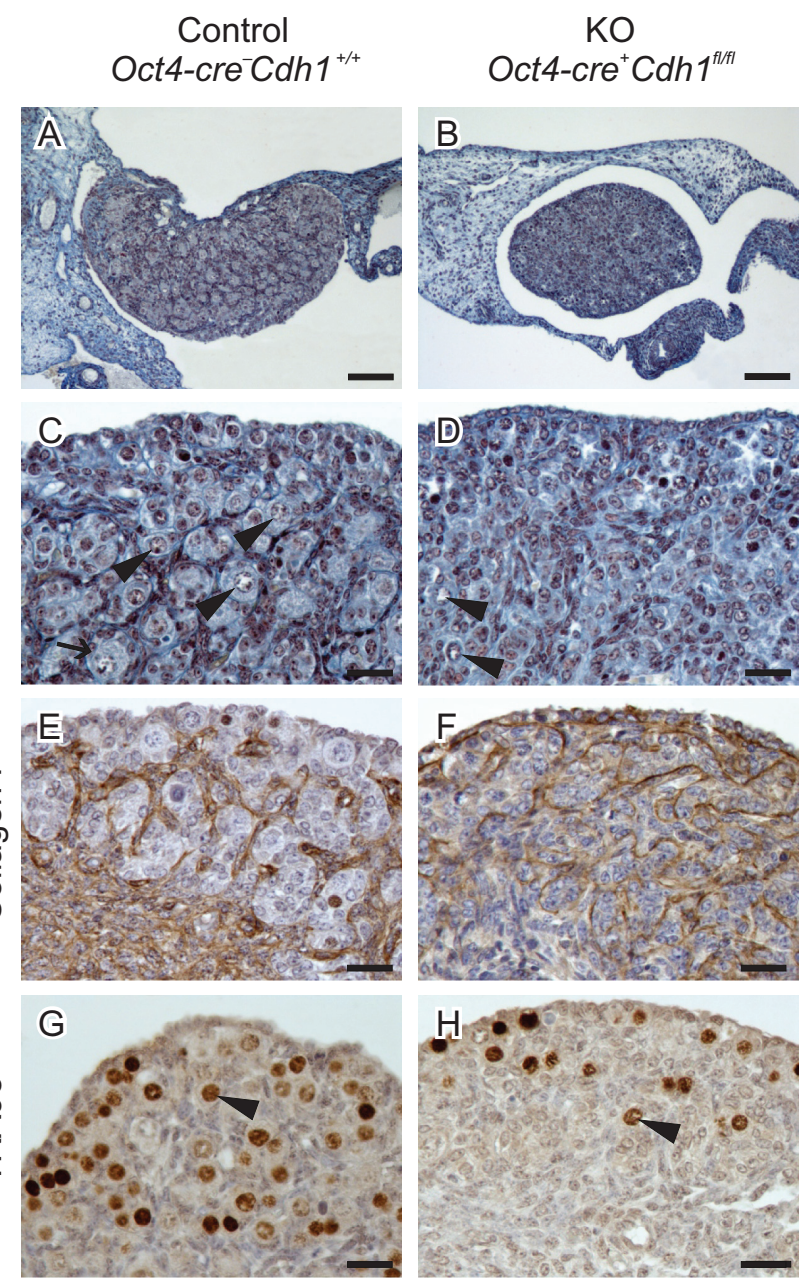

Figure 5 Structure of the ovary in control and E-cadherin knockout in the germ cells at E18.5. Histology (A and C) of the control ovary (Oct4-cre ${ }^{-} \mathrm{Cdh}^{+/+}$) shows the presence of numerous diplotene oocytes (arrowhead), however, oocytes are not visible in the knockout ovaries (B and D, Oct4-cre $\left.{ }^{+} C d h 1^{f l / f l}\right)$. Ovarian follicles (arrow) form near the medullar region of the ovary; trichrome staining. Immunostaining of collagen I in the control (E) and knockout (F) ovaries shows significant differences in the ovarian structure; the ovigerous cords in the control ovary are thicker. ( $\mathrm{G}$ and $\mathrm{H})$ The immunostaining of TRA98 shows that the number of germ cells (arrowheads) is significantly lower in the knockout than in control ovary. Scale bar: A and B: $100 \mu \mathrm{m}$; C, D, E and F: $25 \mu \mathrm{m}$. 

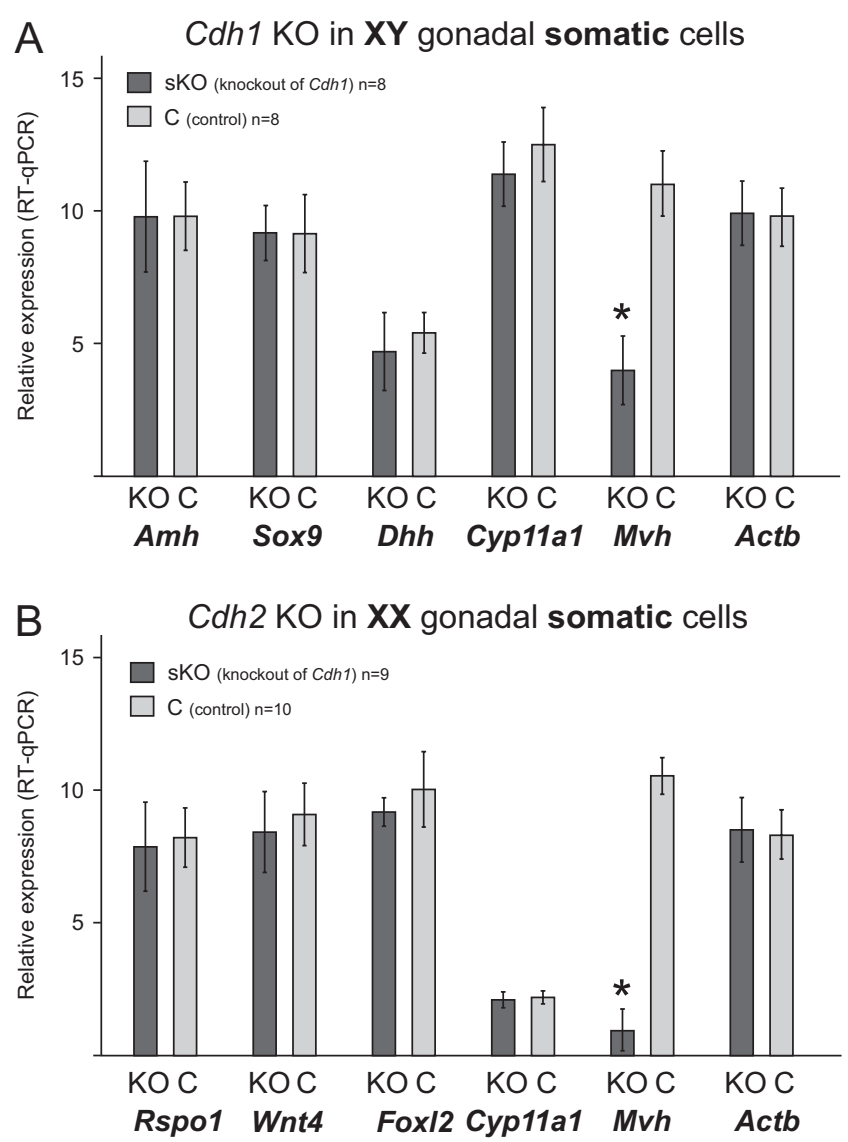

Figure 6 Gene expression in control and E-cadherin knockout in the somatic cells at E18.5. The number of germ cells is significantly lower in knockout $X Y(A)$ and $X X(B)$ gonads than in the control. ${ }^{*} P<0.05$ (by $\left.\chi^{2}\right)$.

cultured in the medium supplemented with anti-Ecadherin antibody (Bendel-Stenzel et al. 2000, Di Carlo $\&$ De Felici 2000). These studies showed that the anti-Ecadherin antibody disrupted PGC-PGC aggregation, led to the ectopic localization of PGCs and decreased the number of germ cells in the gonadal primordia.

In our studies, the knockout of E-cadherin in germ cells led to a significant reduction or complete elimination of the germ cells. This indicates that E-cadherin is important not only for the migration and settlement of the primordial germ in the genital ridges (Bendel-Stenzel et al. 2000, Di Carlo \& De Felici 2000), but also at the later stages of gonadogenesis.

We also showed that the number of germ cells was reduced when $\mathrm{E}$-cadherin was deleted in the $\mathrm{SF} 1^{+}$somatic cells. This indicates that the presence of E-cadherin at the surface of germ cells and adjacent somatic cells (Sertoli and follicular cells) is important for their proper adhesion, correct signaling between somatic and germ cells, and, consequently, for the germ cell fate. We did not detect any significant differences in cell proliferation between knockout and control gonads. Our observation indicates that the germ cell loss in the knockout gonads did not result from impaired proliferation, but rather from
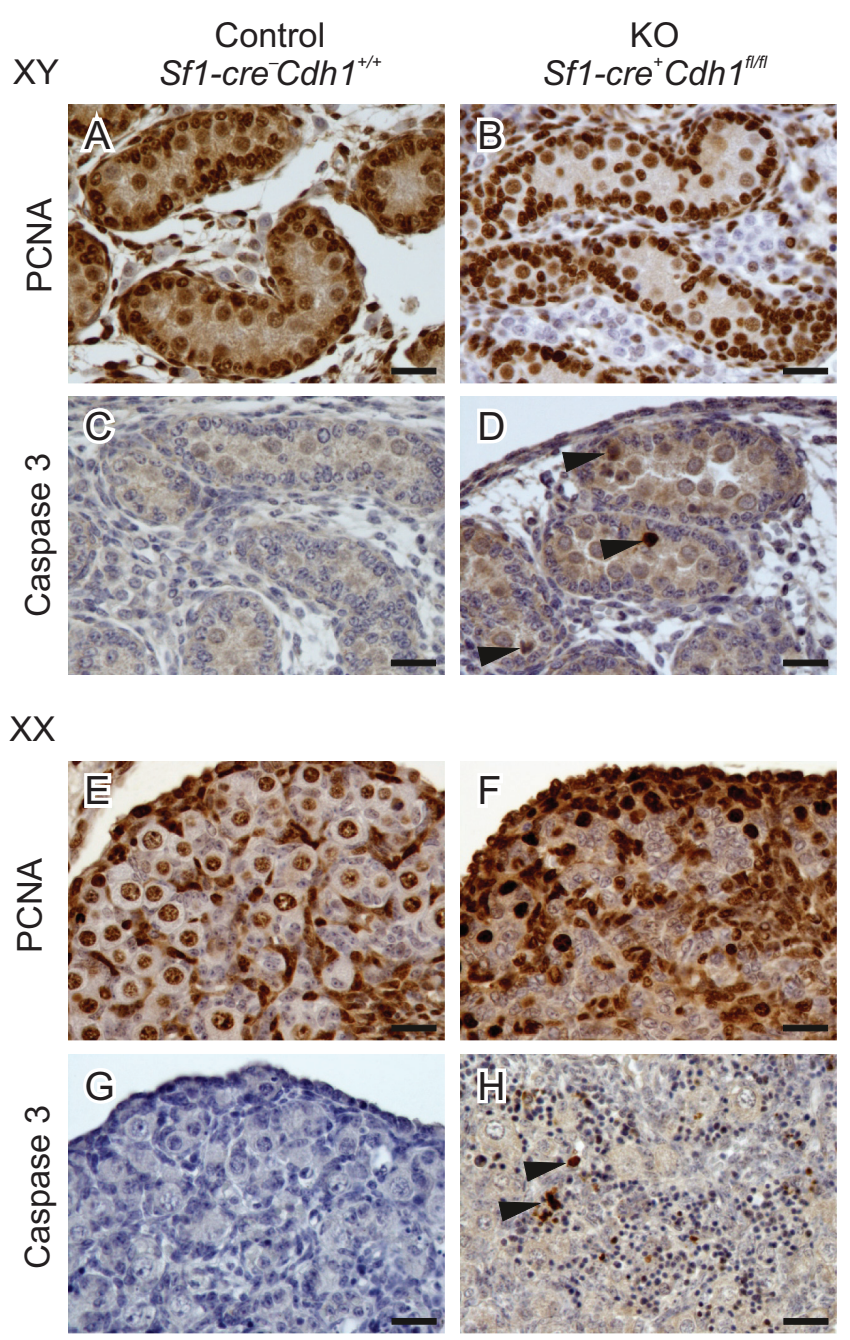

Figure 7 Proliferation (PCNA immunostaining) and apoptosis (caspase 3 immunostaining) in testes and ovaries in E-cadherin knockout in the somatic cells at E18.5. Visibly similar number of PCNA-positive cells is visible in control (A) and knockout testis (B) indicating similar level of proliferation (Supplementary Table 5). Apoptotic (caspase 3 positive) cells (arrowheads) are present in the knockout within the testis cords (D). The control testis cords (C) lack apoptotic cells. The knockout (F) and control ovaries (E) show similar number of PCNA-positive cells, however, caspase 3-positive cells are visibly more numerous in the knockout $(\mathrm{H})$ than in the control $(\mathrm{G})$ ovaries (Supplementary Tables 6 and 8). Scale bar: $25 \mu \mathrm{m}$.

enhanced apoptosis, which we detected in both sexes and both knockouts. The impact of E-cadherin knockout on the adhesion between the somatic and germ cells may potentially induce apoptosis of germ cells. Indeed, it has been shown that E-cadherin-mediated contacts prevent apoptosis in rat granulosa cells (Peluso et al. 2001). Moreover, E-cadherin, either directly or indirectly activates Akt kinase (protein kinase B) activity, which in turn, inactivates caspase 3 and prevents apoptosis (Peluso et al. 2001). In contrast, the loss of E-cadherin inactivates Akt kinase, which leads to the activation of caspase 3 and promotes apoptosis (Peluso et al. 2001). 


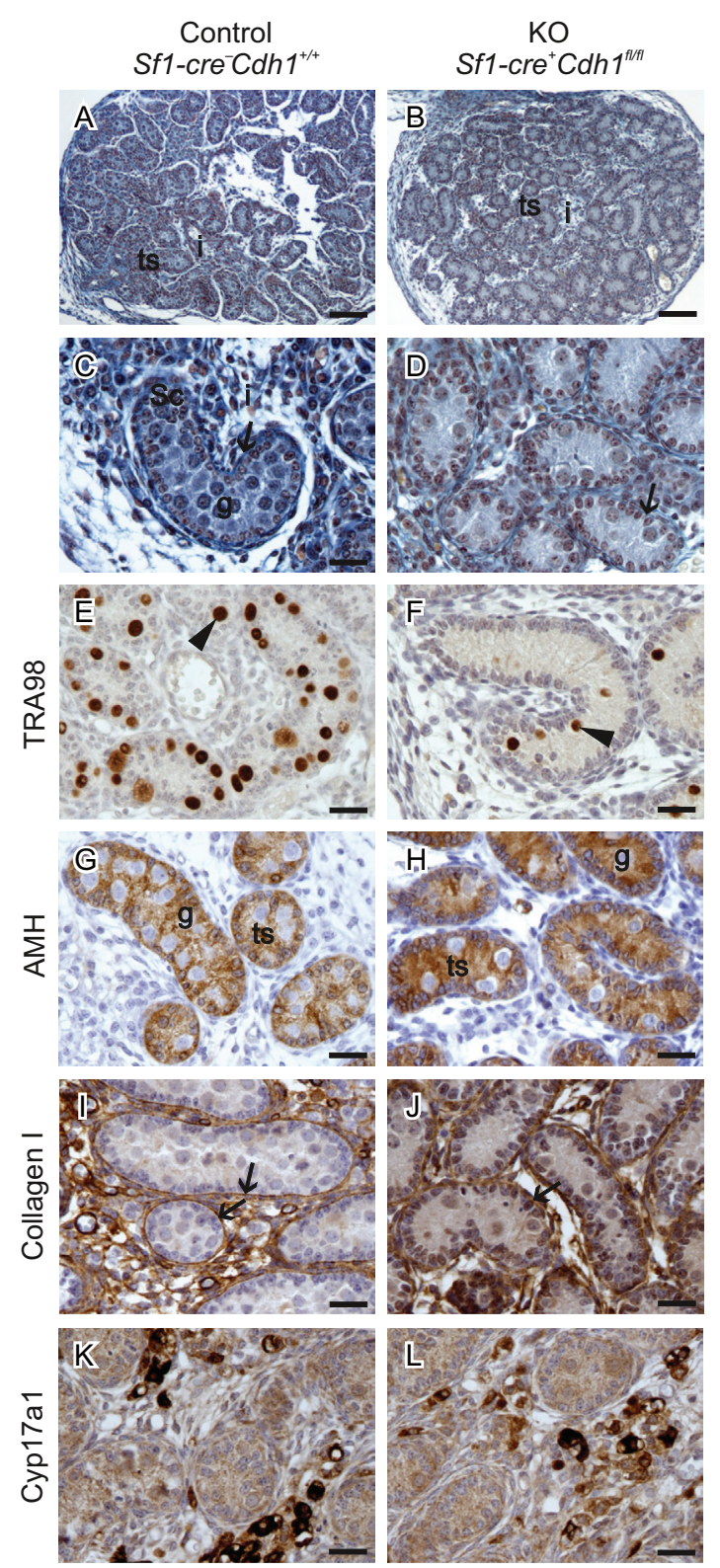

Figure 8 Histology of the testis in control and E-cadherin knockout in the somatic cells. (A and C) Testes of control individual (Sf1-Cre- $\mathrm{Cdh} \mathrm{T}^{+/+}$) at stage E18.5; germ cells (g) are enclosed by the Sertoli cells (Sc); the whole testis cord (ts) is encapsulated by basement membrane (arrow); interstitium (i) is located between the cords; trichrome staining. (B and D) The knockout testis $\left(S f 1-\mathrm{Cre}^{+} \mathrm{Cdh} 1^{\mathrm{fl} / \mathrm{f} f}\right)$ have similar tote control stucture however, in the knockout testis the number of germ cells $(\mathrm{g})$ is visibly lower; trichrome staining. ( $E$ and $F$ ) The immunostaining of TRA98 shows that the number of germ cells (arrowheads) is significantly lower in the knockout than in control testis. The immunostaining of $\mathrm{AMH}$ in the control $(\mathrm{G})$ and knockout testis $(\mathrm{H})$ is similar, however, the knockout testis cords contain only the Sertoli cells and the germ cells (g) cells are very rare. Immunostaining of collagen I shows integrity of the testis cords and the presence of continuous basement membranes (arrows) enclosing each testis cord in control (I) and knockout (J) testes. No significant differences are present in Cyp17a1 immunostaining in control (K) and knockout (L) testes. Cyp17a1-positive cells are fetal Leydig cells visible in the interstitium. Scale bar: A and B: $100 \mu \mathrm{m} ; \mathrm{C}, \mathrm{D}$, E, F, G, H, I and J: $25 \mu \mathrm{m}$.
Control Sf1-cre-Cdh1 $1^{+/+}$
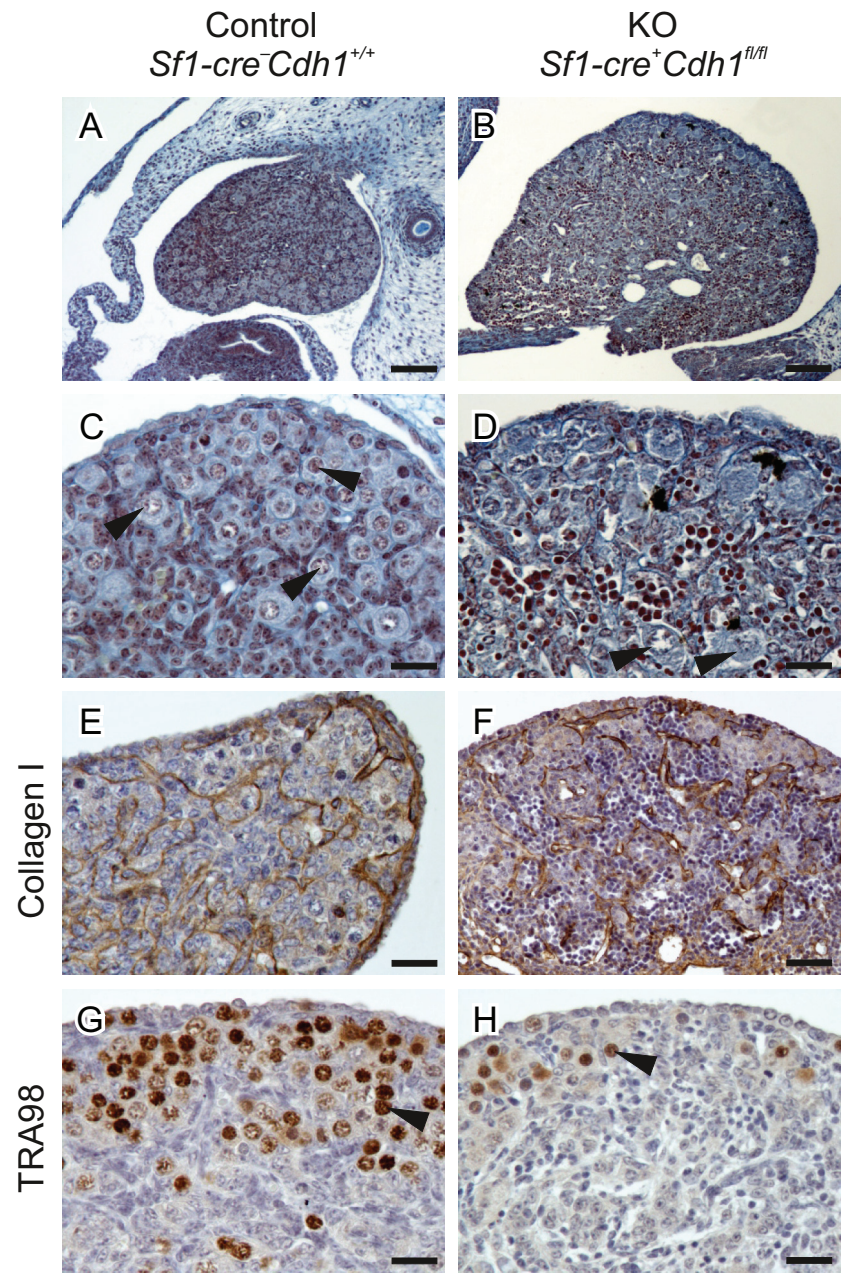

Figure 9 Structure of the ovary in control and E-cadherin knockout in the somatic cells at E18.5. Histology (A and C) of the control ovary (Sf1-cre- $C \mathrm{C} h \mathrm{1}^{+/+}$) shows presence of numerous diplotene oocytes (arrowheads), however, in the knockout ovaries (B and D, Sf1-Cre $\mathrm{C}^{+}$ $\left.C d h 1^{f / / f l}\right)$ the oocytes are absent; trichrome staining. Immunostaining of collagen I in the control (E) and knockout (F) ovaries shows borders between the ovigerous cords. In the knockout ovaries the cords are smaller. (G and $\mathrm{H}$ ) The immunostaining of TRA98 shows that the number of germ cells (arrowheads) is significantly lower in the knockout than in control ovary. Scale bar: A and B: $100 \mu \mathrm{m} ; \mathrm{C}, \mathrm{D}$, E and $\mathrm{F}: 25 \mu \mathrm{m}$.

The loss of E-cadherin was also shown to be involved in the induction of apoptosis in mouse skin epithelial cells and enterocytes (Fouquet et al. 2004, Galaz et al. 2005). Further studies are necessary to resolve whether the loss of E-cadherin in the germ cells induce apoptosis via inactivation of Akt kinase or by a different mechanism.

We showed that the germ cell loss in E-cadherin knockout in both germ or gonadal somatic cells started at stage E16.5. This suggests that the presence of E-cadherin around the embryonic day 16.5 is critical for germ cell survival. In developing female gonad, the germ cells are located within the germ cell cysts. The majority of germ cells enter meiosis at stage E15.5. At stage E17.5 some of the germ cells enter diplotene and the germ cysts brake 
down into the ovarian follicles (Borum 1961, Pepling \& Spradling 2001, Pepling et al. 2010). We also observed that the germ cells loss in the male gonads also occurred at the same time that is at stage E16.5. In the testes around E16.5, the germ cells enter G0 mitotic arrest (McLaren 2003, Töhönen et al. 2003). Further studies are needed to understand why the proper cell adhesion at this particular period of development is critical for the survival of germ cells in the male and female gonad.

We also showed that the depletion of E-cadherin in $\mathrm{SF}^{+}{ }^{+}$somatic cells did not alter the formation of the testis cords or the ovigerous cords. This indicates that E-cadherin-mediated adhesion is not important for the differentiation and formation of the somatic component of the gonads or for the maintenance of testis cords integrity. Other studies showed that certain extracellular matrix components such as collagen IV seem to be crucial for the integrity of the testis cords. Chen et al. (2013) showed that a deletion of Wt1 (Wilms tumor 1 gene) in Sertoli cells of developing mouse testes led to the disruption of testis cords due to the decreased expression of Col4a 1 and Col4a2 genes (the expression of E-cadherin and other CAMs remained unchanged) (Chen et al. 2013). It is known that cadherins are involved in WNT/ $\beta$-catenin pathway that is pivotal for female sex determination in the mouse (reviewed by Piprek 2009a,b). Thus, the knockout of E-cadherin in developing gonads could possibly disrupt sex determination. Surprisingly, in the knockout gonads in our study, the expression of male and female sexdetermining genes agreed with the genetic sex, and the sex ratio was not altered. This indicates that the lack of E-cadherin did not affect sex determination.

\section{Supplementary data}

This is linked to the online version of the paper at https://doi.org/10.1530/REP-18-0621.

\section{Declaration of interest}

The authors declare that there is no conflict of interest that could be perceived as prejudicing the impartiality of the research reported.

\section{Funding}

The study was conducted within the project financed by the Polish National Science Centre (NCN) assigned on the basis of the decision number DEC-2014/15/B/NZ3/02316.

\section{References}

Albrecht KH \& Eicher EM 2001 Evidence that Sry is expressed in preSertoli cells and Sertoli and granulosa cells have a common precursor. Developmental Biology $240 \quad 92-107 . \quad$ (https://doi.org/10.1006/ dbio.2001.0438)
Beavon IRG 2000 The E-cadherin-catenin complex in tumour metastasis: structure, function and regulation. European Journal of Cancer 36 1607-1620. (https://doi.org/10.1016/S0959-8049(00)00158-1)

Bendel-Stenzel MR, Gomperts M, Anderson R, Heasman J \& Wylie C 2000 The role of cadherins during primordial germ cell migration and early gonad formation in the mouse. Mechanisms of Development 91 143-152. (https://doi.org/10.1016/S0925-4773(99)00287-7)

Borum K 1961 Oogenesis in the mouse: a study of the meiotic prophase. Experimental Cell Research 24 495-507. (https://doi.org/10.1016/00144827(61)90449-9)

Boussadia O, Kutsch S, Hierholzer A, Delmas V \& Kemler R 2002 E-cadherin is a survival factor for the lactating mouse mammary gland. Mechanisms of Development 115 53-62. (https://doi.org/10.1016/ S0925-4773(02)00090-4)

Chen SR \& Liu YX 2016 Testis cord maintenance in mouse embryos: genes and signaling. Biology of Reproduction 94 42. (https://doi.org/10.1095/ biolreprod.115.137117)

Chen SR, Chen M, Wang XN, Zhang J, Wen Q, Ji SY, Zheng QS, Gao F \& Liu YX 2013 The Wilms tumor gene, Wt1, maintains testicular cord integrity by regulating the expression of Col4a 1 and Col4a2. Biology of Reproduction 88 1. (https://doi.org/10.1095/ biolreprod.112.105379)

DeFalco T, Takahashi S \& Capel B 2011 Two distinct origins for Leydig cell progenitors in the fetal testis. Developmental Biology 352 14-26. (https://doi.org/10.1016/j.ydbio.2011.01.011)

Dhillon H, Zigman JM, Ye C, Lee CE, McGovern RA, Tang V, Kenny CD, Christiansen LM, White RD, Edelstein EA et al. 2006 Leptin directly activates $\mathrm{SF}^{+}{ }^{+}$neurons in the $\mathrm{VMH}$, and this action by leptin is required for normal body-weight homeostasis. Neuron 49 191-203. (https://doi. org/10.1016/j.neuron.2005.12.021)

Di Carlo A \& De Felici M 2000 A role for E-cadherin in mouse primordial germ cell development. Developmental Biology 226 209-219. (https:// doi.org/10.1006/dbio.2000.9861)

Durcova-Hills G, Tokunaga T, Kurosaka S, Yamaguchi M, Takahashi S \& Imai H 1999 Immunomagnetic isolation of primordial germ cells and the establishment of embryonic germ cell lines in the mouse. Cloning 1 217-224. (https://doi.org/10.1089/15204559950019852)

Fouquet S, Lugo-Martínez VH, Faussat AM, Renaud F, Cardot P, Chambaz J, Pincon-Raymond M \& Thenet S 2004 Early loss of E-cadherin from cellcell contacts is involved in the onset of anoikis in enterocytes. Journal of Biological Chemistry 279 43061-43069. (https://doi.org/10.1074/jbc. M405095200)

Fujikawa T, Castorena CM, Pearson M, Kusminski CM, Ahmed N, Battiprolu PK, Kim KW, Lee S, Hill JA, Scherer PE et al. 2016 SF-1 expression in the hypothalamus is required for beneficial metabolic effects of exercise. elife 5 e18206. (https://doi.org/10.7554/ eLife.18206)

Galaz S, Espada J, Stockert JC, Pacheco M, Sanz-Rodríguez F, Arranz R, Rello S, Canete M, Villanueva A, Esteller M et al. 2005 Loss of E-cadherin mediated cell-cell adhesion as an early trigger of apoptosis induced by photodynamic treatment. Journal of Cellular Physiology 205 86-96. (https://doi.org/10.1002/jcp.20374)

Greder LV, Gupta S, Li S, Abedin MJ, Sajini A, Segal Y, Slack JMW \& Dutton JR 2012 Analysis of endogenous Oct4 activation during induced pluripotent stem cell reprogramming using an inducible Oct4 lineage label. Stem Cells 30 2596-2601. (https://doi.org/10.1002/stem.1216)

Huang K, Wang Y, Zhang T, He M, Sun G, Wen J, Yan H, Cai H, Yong C, Xia $\mathbf{G}$ et al. 2018 JAK signaling regulates germline cyst breakdown and primordial follicle formation in mice. Biology Open 7 bio029470. (https://doi.org/10.1242/bio.029470)

Ikeda Y, Shen WH, Ingraham HA \& Parker KL 1994 Developmental expression of mouse steroidogenic factor-1, an essential regulator of the steroid hydroxylases. Molecular Endocrinology 8 654-662. (https://doi. org/10.1210/mend.8.5.8058073)

Kiernan JA 1990 Histological and Histochemical Methods: Theory and Practice, 2nd ed. Oxford, New York, Seoul, Tokyo: Pergamon Press. (https://doi.org/10.4081/ejh.2016.2639)

Kumar TR, Palapattu G, Wang P, Woodruff TK, Boime I, Byrne MC \& Matzuk MM 1999 Transgenic models to study gonadotropin function: the role of follicle-stimulating hormone in gonadal growth and tumorigenesis. Molecular Endocrinology 13 851-865. (https://doi. org/10.1210/mend.13.6.0297) 
Larue L, Ohsugi M, Hirchenhain J \& Kemler R 1994 E-cadherin null mutant embryos fail to form a trophectoderm epithelium. PNAS 91 8263-8267. (https://doi.org/10.1073/pnas.91.17.8263)

Liu C, Peng J, Matzuk MM \& Yao HHC 2015 Lineage specification of ovarian theca cells requires multicellular interactions via oocyte and granulosa cells. Nature Communications 6 6934. (https://doi. org/10.1038/ncomms7934)

Mackay S, Nicholson CL, Lewis SP \& Brittan M 1999 E-cadherin in the developing mouse gonad. Anatomy and Embryology 200 91-102. (https://doi.org/10.1007/s004290050263)

McFarlane L, Truong V, Palmer JS \& Wilhelm D 2013 Novel PCR assay for determining the genetic sex of mice. Sexual Development 7 207-211. (https://doi.org/10.1159/000348677)

McLaren A 2003 Primordial germ cells in the mouse. Developmental Biology 262 1-15. (https://doi.org/10.1016/S0012-1606(03)00214-8)

Ohsugi M, Larue L, Schwarz H \& Kemler R 1997 Cell-junctional and cytoskeletal organization in mouse blastocysts lacking E-cadherin. Developmental Biology 185 261-271. (https://doi.org/10.1006/ dbio.1997.8560)

Peluso J, Pappalardo A \& Fernandez G 2001 E-cadherin-mediated cell contact prevents apoptosis of spontaneously immortalized granulosa cells by regulating Akt kinase activity. Biology of Reproduction 64 1183-1190. (https://doi.org/10.1095/biolreprod64.4.1183)

Pepling ME \& Spradling AC 2001 Mouse ovarian germ cell cysts undergo programmed breakdown to form primordial follicles. Developmental Biology 234 339-351. (https://doi.org/10.1006/dbio.2001.0269)

Pepling ME, Sundman EA, Patterson NL, Gephardt GW, Medico L \& Wilson KI 2010 Differences in oocyte development and estradiol sensitivity among mouse strains. Reproduction 139 349-357. (https:// doi.org/10.1530/REP-09-0392)

Piprek RP 2009a Genetic mechanisms underlying male sex determination in mammals. Journal of Applied Genetics 50 347-360. (https://doi. org/10.1007/BF03195693)

Piprek RP 2009b Molecular mechanisms underlying female sex determination-antagonism between female and male pathway. Folia Biologica 57 105-113. (https://doi.org/10.3409/fb57_3-4.105-113)

Piprek RP, Pecio A \& Szymura JM 2010 Differentiation and development of gonads in the yellow-bellied toad, Bombina variegata L., 1758 (Amphibia: Anura: Bombinatoridae). Zoological Science 27 47-55. (https://doi.org/10.2108/zsj.27.47)

Piprek RP, Pecio A, Kubiak JZ \& Szymura JM 2012 Differential effects of busulfan on gonadal development in five divergent anuran species. Reproductive Toxicology $34 \quad 393-401$. (https://doi.org/10.1016/j. reprotox.2012.05.002)
Piprek RP, Kloc M \& Kubiak JZ 2016 Early development of the gonads: origin and differentiation of the somatic cells of the genital ridges. In Molecular Mechanisms of Cell Differentiation in Gonad Development, pp 1-22. Cham: Springer. (https://doi.org/10.1007/978-3-319-31973-5_1)

Piprek RP, Kolasa M, Podkowa D, Kloc M \& Kubiak JZ $2017^{-}$Cell adhesion molecules expression pattern indicates that somatic cells arbitrate gonadal sex of differentiating bipotential fetal mouse gonad. Mechanisms of Development 147 17-27. (https://doi.org/10.1016/j. mod.2017.07.001)

Polyak K \& Weinberg RA 2009 Transitions between epithelial and mesenchymal states: acquisition of malignant and stem cell traits. Nature Reviews: Cancer 9 265-273. (https://doi.org/10.1038/nrc2620)

Svingen T, Spiller CM, Kashimada K, Harley VR \& Koopman P 2009 Identification of suitable normalizing genes for quantitative real-time RT-PCR analysis of gene expression in fetal mouse gonads. Sexual Development 3 194-204. (https://doi.org/10.1159/000228720)

Themmen APN \& Huhtaniemi IT 2000 Mutations of gonadotropins and gonadotropin receptors: elucidating the physiology and pathophysiology of pituitary-gonadal function. Endocrine Reviews 21 551-583. (https:// doi.org/10.1210/edrv.21.5.0409)

Tiptanavattana N, Radtanakatikanon A, Hyttel P, Holm H, Buranapraditkun S, Setthawong P, Techakumphu M \& Tharasanit T 2015 Determination phase at transition of gonocytes to spermatogonial stem cells improves establishment efficiency of spermatogonial stem cells in domestic cats. Journal of Reproduction and Development 61 581-588. (https://doi.org/10.1262/jrd.2015-094)

Töhönen V, Ritzen EM, Nordqvist K \& Wedell A 2003 Male sex determination and prenatal differentiation of the testis. In The Developing Testis, Vol. 5, pp 1-23. Karger Publishers. (https://doi.org/10.1159/000069299)

van Roy F \& Berx G 2008 The cell-cell adhesion molecule E-cadherin. Cellular and Molecular Life Sciences 65 3756-3788. (https://doi. org/10.1007/s00018-008-8281-1)

Zhao L, Bakke M \& Parker KL 2001 Pituitary-specific knockout of steroidogenic factor 1. Molecular and Cellular Endocrinology 185 27-32. (https://doi.org/10.1016/S0303-7207(01)00621-9)

Received 9 December 2018

First decision 31 January 2019

Revised manuscript received 8 May 2019

Accepted 16 May 2019 